\title{
Latent class analysis on internet and smartphone addiction in college students
}

\author{
This article was published in the following Dove Press journal: \\ Neuropsychiatric Disease and Treatment \\ 20 May 2014 \\ Number of times this article has been viewed
}

\author{
Jung-Yeon Mok' \\ Sam-Wook Choi ${ }^{1,2}$ \\ Dai-Jin Kim ${ }^{3}$ \\ Jung-Seok $\mathrm{Choi}^{4}$ \\ Jaewon Lee ${ }^{2}$ \\ Heejune $\mathrm{Ahn}^{5}$ \\ Eun-Jeung Choi ${ }^{6}$ \\ Won-Young Song ${ }^{7}$
}

'Eulji Addiction Institute, Eulji University, Seoul, South Korea;

${ }^{2}$ Department of Psychiatry, Gangnam

Eulji Hospital, Eulji University,

Seoul, South Korea; ${ }^{3}$ Department of

Psychiatry, Seoul St Mary's Hospital,

College of Medicine, Catholic

University of Korea, Seoul, South

Korea; ${ }^{4}$ Department of Psychiatry,

SMG-SNU Boramae Medical Center,

Seoul, South Korea; ${ }^{5}$ Department

of Electrical and Information

Engineering, SeoulTech, Seoul, South

Korea; ${ }^{6}$ Department of Social Welfare,

Dongshin University, Naju, South

Korea; ${ }^{7}$ Department of Counseling

and Psychotherapy, Konyang

University, Nonsan, South Korea
Correspondence: Sam-Wook Choi Gangnam Eulji Hospital, Eulji University, 202 Dosan-daero, Gangnam-gu, Seoul,

I35-816, South Korea

Tel +8223438 I I 2 I

Fax +82 23438 I00 I

Email peaceinu@hanmail.net
Purpose: This study aimed to classify distinct subgroups of people who use both smartphone and the internet based on addiction severity levels. Additionally, how the classified groups differed in terms of sex and psychosocial traits was examined.

Methods: A total of 448 university students (178 males and 270 females) in Korea participated. The participants were given a set of questionnaires examining the severity of their internet and smartphone addictions, their mood, their anxiety, and their personality. Latent class analysis and ANOVA (analysis of variance) were the statistical methods used.

Results: Significant differences between males and females were found for most of the variables (all $P<0.05$ ). Specifically, in terms of internet usage, males were more addicted than females $(P<0.05)$; however, regarding smartphone, this pattern was reversed $(P<0.001)$. Due to these observed differences, classifications of the subjects into subgroups based on internet and smartphone addiction were performed separately for each sex. Each sex showed clear patterns with the three-class model based on likelihood level of internet and smartphone addiction $(P<0.001)$. A common trend for psychosocial trait factors was found for both sexes: anxiety levels and neurotic personality traits increased with addiction severity levels (all $P<0.001$ ). However, Lie dimension was inversely related to the addiction severity levels (all $P<0.01$ ).

Conclusion: Through the latent classification process, this study identified three distinct internet and smartphone user groups in each sex. Moreover, psychosocial traits that differed in terms of addiction severity levels were also examined. It is expected that these results should aid the understanding of traits of internet and smartphone addiction and facilitate further study in this field.

Keywords: sex difference, Eysenck personality type, psychosocial traits

\section{Introduction Internet addiction}

Internet addiction is defined as the inability to control one's internet use and is a condition that results in the serious impairment of various life functions. ${ }^{1-4}$ Over the last 2 decades, the global internet-using population has grown to almost 2.5 billion. ${ }^{5}$ It is an undeniable fact that internet brings many benefits to our lives. However, emerging evidence associated with various negative consequences indicates that excessive internet use can be problematic for some individuals. ${ }^{6,7}$ The psychological consequences involve the following: obsession for the internet or internet gaming; imbalance of real-life relationships, sleep, work, and education; ${ }^{8-15}$ increased aggression, hostility, and stress $;{ }^{8,16,17}$ problems with verbal memory and attention; $; 8,17,18$ maladaptive coping strategies; ${ }^{8,19,20}$ and low wellbeing and high loneliness. ${ }^{21}$ In addition, psychosomatic 
and neuro-anatomic studies on internet addiction have been accumulated to widen the understanding of the possible relationship between brain alteration and internet addiction. ${ }^{8,22}$

Although discrepancies in measurements, as well as the different cutoff points, reliability problems of self-reporting formats, and culturally limited studies, make some researchers still cast doubt on diagnosis of internet addiction, the disorder is now considered as one of the behavior addictions. ${ }^{23,24}$ Indeed, in May 2013, internet addiction was included in an appendix of the newly updated version of the Diagnostic and Statistical Manual for Mental Disorders (DSM-5) as a new term, "internet Gaming Disorder." This would indicate the fact that the American Psychiatric Association has officially approved internet gaming disorder as a condition that requires consideration of clinicians and researchers, like other behavioral addictions. ${ }^{25}$ Furthermore, as development of internet-based smart-mobile devices increases, the significance of this research is likely to increase.

\section{Smartphone addiction}

With abundant applications, smartphones provide users with internet-based communication, business trading, education, entertainment media, and even clinical applications. Given their variety of functions and ease of use, the number of estimated global users was more than 1.08 billion in early 2012 , and it is increasing with great speed. However, smartphones can be problematic when used excessively. For example, excessive smartphone use can cause maladaptive behavioral difficulties seen in impulse control disorders in general or pathological gambling; it can interfere with school or work, ${ }^{26}$ decrease real-life social interaction, decrease academic ability, cause relationship problems, ${ }^{27}$ and cause physical health-related problems including blurred vision and pain in the wrists or the back of the neck. ${ }^{28}$

Most behaviors performed under conscious control are selected to fulfil one's social, functional, and psychological needs. Therefore, when a behavior brings a satisfaction to an individual, it is actively continued and habituated. In this sense, it is difficult to simply class habitual smartphone usage as an addiction-like behavior. However, according to previous studies, ${ }^{29,30}$ problematic smartphone use could be included in the behavior addiction category when the following components of addiction are taken into consideration: 1) the individual is preoccupied with a specific behavior (smartphone use); 2) the behavior is used in order to escape reality or create a feeling of euphoria; 3 ) as the behavior is continued, tolerance develops; 4) when the behavior is abstained or interfered with, withdrawal symptoms occur (feeling anxious, depressed, or irritable); 5) as a consequence of the continuous behavior, interpersonal problems occur; and 6) individual experiences relapse against one's will. Previous studies have indeed found that smartphones are addictive for users and are closely attached to their lives. A Taiwanese study of 10,191 adolescents reported that $30 \%$ of participants exhibited tolerance, $36 \%$ exhibited withdrawal, $27 \%$ exhibited use that was heavier than intended, $18 \%$ made unsuccessful attempts to reduce, and $10 \%$ experienced functional impairment of close relationships. ${ }^{31}$

It is true that many authorities carefully acknowledge that there certainly is a risk of addiction due to the excessive use or misuse of a smartphone. However, because of the limited findings, which lack a validated standard, nothing about smartphone addiction or the characteristics of problematic users has yet been clearly concluded. Meanwhile, a main feature of the smartphone is the operation of internet-based applications; thus, smartphone use must share many functional or psychological properties with internet use. Therefore, based on the possible relationship, investigating smartphone addiction in relation to internet addiction by integrative study would be reasonable.

\section{Objectives}

Although some clinicians have intuitively demonstrated the association between internet and smartphone addiction, little research has been performed. Considering the current lack of reliable diagnostic indicators and validated cutoff standards for internet and smartphone addiction, this present study will contribute to the literature by specifically exploring the relationship between internet and smartphone addiction and the unique characteristics of addictive users.

In this study, we firstly categorized internet and smartphone users into groups based on their addiction severities. Crosssectional comparisons of the profiles were then performed on psychological traits of each group. Moreover, before the main analysis, we empirically confirmed the existence of a difference between male and female internet and smartphone addiction levels. Female participants were more prone to smartphone addiction, and male participants exhibited highly addictive patterns toward both the internetand internet gaming. Therefore, we decided to analyze the data separately for each sex to eliminate systematic effects from the results.

\section{Materials and methods Participants}

A total of 463 Korean college students from Seoul $(n=78$, $16.9 \%)$, Sungnam $(n=154,33.3 \%)$, Nonsan $(n=76,16.4 \%)$, 
and Daejeon ( $\mathrm{n}=155,33.5 \%)$ participated in the study. Data from 15 participants were excluded because more than $50 \%$ of the values were missing. All participants who met the inclusion criteria for internet and smartphone use were retained for the analyses.

\section{Procedures}

Ethical approval was obtained from the Institutional Review Board of Eulji University Hospital prior to data collection (reference 12-068). Detailed research and instruction packages were sent to four universities in Korea. This package requested the allocation of 60-70 minutes of in-class testing time to complete the questionnaires. Written informed consent was attained from all participants prior to participation. Participants were informed that they were not obliged to participate, that all responses were anonymous, and that they were free to refuse to answer any questions.

\section{Measurements}

Respondents completed a number of validated screening tools for demographic information (age, academic year, and sex), internet addiction, smartphone addiction, mood, anxiety, and personality. All questionnaires were in the selfreport format.

\section{Internet addiction}

Young's Internet Addiction Test (IAT) ${ }^{1}$ has been widely used to screen for internet addiction. The IAT contains 20 items and assesses productivity (work, school, or home), social behaviors, emotional connection, and general patterns of internet use. The items are rated on a 5 -point scale $(1=$ very rarely and $5=$ very frequently) and produce an overall score of between 20 and 100 . The Cronbach's alpha coefficient for the IAT is 0.94 .

\section{Smartphone addiction}

The Smartphone Addiction Scale (SAS) ${ }^{28}$ contains six subscales of problematic smartphone usage (daily-lifedisturbance, positive-anticipation, withdrawal, overuse, tolerance, and cyberspace-oriented relationship). The SAS also yields a total score that is indicative of the severity of smartphone addiction; higher scores indicate more severe addictions. The SAS has 33 items that rate on 6-point scales from 1 (strongly disagree) to 6 (strongly agree). The Cronbach's alpha coefficient for the SAS is 0.967 .

\section{Depression}

Beck's Depression Inventory (BDI)- ${ }^{32}$ is composed of 21 items that evaluate the degree of depression. Each question inquires about the respondent's particular symptoms and changes in mood over the past week, with a 4-point scale. The severity of depression is indicated by the total score. The Cronbach's alpha coefficient of the BDI-I is 0.91 , and that of the Korean version of the BDI-I is $0.85 .{ }^{33}$

\section{Anxiety}

The State-Trait Anxiety Inventory, Trait Version (STAI-T) ${ }^{34}$ is a validated self-report measure with 20 items that are rated from 1 (not at all) to 4 (very much). The STAI-T is one of the most widely used tools for examining individual differences in anxiety personality traits. Various studies of the STAI-T have confirmed that it is an appropriate and adequate measure for studying anxiety in research and clinical settings. ${ }^{35}$ The internal consistency coefficient of the Korean version of STAI-T is $0.88 .^{36}$

\section{Personality}

The Eysenck Personality Questionnaire (EPQ) ${ }^{37}$ measures individuals' personalities across four dimensions: psychoticism, extroversion-introversion, neuroticism/anxiety, and social desirability (a Lie scale). The original English version contains 90 items; however, the Korean version has 79 items because some irrelevant items were removed. ${ }^{38}$ Of these 79 items, the psychoticism scale contains 15 items, the extroversion scale contains 20 items (two with reversed answers), the neuroticism scale contains 24 items, and the Lie scale is measured with 20 items ( 15 with reversed answers). The EPQ questions elicit dichotomous responses (yes or no). The Cronbach's alpha coefficients that have been reported for the four scales are as follows: psychoticism, 0.82-0.95; extraversion, 0.98-1.00; neuroticism, 0.82-0.95; and Lie scale, $0.97-0.99$.

\section{Data analyses}

Data analyses were performed in the following phases: 1) descriptive analysis (means, standard deviations, and proportions) was performed to examine the distributions of the variables; 2) latent class analysis (LCA), ie, subgrouping based on internet and smartphone addiction; and 3) analysis of variance (ANOVA) and post hoc tests of latent classes.

\section{LCA}

Because the goal of this research was to identify subgroups of individuals who use both a smartphone and the internet, we employed LCA by using the Latent Gold 4.5 (Statistical Innovations Inc., Bermont, MA, USA) software. ${ }^{39}$ Unlike correlation studies that include parameters only describing 
relationships among observed variables, latent analysis models can be used to find latent and homogeneous populations and meaningful groups of profiles. ${ }^{40,41}$ Because LCA assesses individual probabilities and makes decisions regarding the best-fitting latent classes, class memberships are mutually exclusive, and individuals within a class are homogeneous.

Identifying the model with the optimal number of latent classes is a critical step for the whole analysis. In this study, models with one to six class solutions were considered, and the overall fits produced by these models were compared. Model fits were examined using the Bayesian information criterion (BIC), Bozdogan's criterion (consistent Akaike's information criterion [CAIC]), and Akaike's information criterion (AIC). Because the BIC provides a relatively qualified measure of overall model fit, it was our primary measure for comparing classes. ${ }^{42}$ Lower BIC and CAIC values indicate better model fits. However, it is also important that the extracted LCA solution produces logically meaningful and distinctive patterns.

\section{Cross-class comparison}

After the best model was selected, psychosocial factors were compared across the classified subgroups. The comparisons were performed with nonparametric statistics, $\chi^{2}$-tests (for categorical variables), and ANOVAs (for continuous variables). When the tests produced significant differences, post hoc analyses with Bonferroni tests were used to examine these differences. The level of significance was set to $\alpha=0.05$, and the SPSS (IBM Corporation, Armonk, NY, USA) version 18.0 statistical software package was used.

\section{Results}

\section{Descriptive statistics (Phase I)}

After an initial examination of the data, 448 college students were included (male $=178,39.7 \%$; female $=270,60.3 \%$ ). The age distributions of each sex were similar (male, mean $[\mathrm{M}]=21.80$, standard deviation $[\mathrm{SD}]=3.39$; female, $\mathrm{M}=20.38, \mathrm{SD}=2.45)$. The participants were equally sampled from in terms of academic grade level (first year $=27 \%$, second year $=18 \%$, third year $=32 \%$, fourth year $=21.4 \%$ ).

As observed in Table 1, most of the variables were significantly different between each sex, with the exception of a couple of personality factors (psychoticism and extroversion). The female participants were more depressed and insecure than the males. Regarding internet usage, the male participants were more addicted than the female participants, and this pattern was reversed for smartphone usage.
Table I Means and standard deviations of the variables between sexes

\begin{tabular}{|c|c|c|c|c|}
\hline \multirow[t]{2}{*}{ Variable } & \multicolumn{2}{|l|}{ Mean (SD) } & \multirow[t]{2}{*}{$P$-value } & \multirow[t]{2}{*}{$\boldsymbol{F}$} \\
\hline & $\begin{array}{l}\text { Male } \\
(n=178)\end{array}$ & $\begin{array}{l}\text { Female } \\
(n=270)\end{array}$ & & \\
\hline Depression & $15.58(10.75)$ & $19.58(13.40)$ & 0.001 & 11.127 \\
\hline Anxiety & $41.60(9.68)$ & $45.69(9.42)$ & $<0.000 \mathrm{I}$ & 19.780 \\
\hline Internet addiction & 35.65 (1 I.72) & $32.91(10.58)$ & 0.011 & 6.588 \\
\hline $\begin{array}{l}\text { Smartphone } \\
\text { addiction }\end{array}$ & $59.65(21.08)$ & $74.67(25.50)$ & $<0.0001$ & 42.408 \\
\hline \\
\hline Psychoticism & $2.94(2.57)$ & $2.97(1.49)$ & 0.875 & 0.025 \\
\hline Extroversion & $10.90(4.20)$ & $10.49(3.8 \mathrm{I})$ & 0.290 & 1.124 \\
\hline Neuroticism & $12.19(5.33)$ & $15.53(4.64)$ & $<0.0001$ & 49.527 \\
\hline $\begin{array}{l}\text { Social } \\
\text { desirability (Lie) }\end{array}$ & $2.44(1.31)$ & $2.08(1.24)$ & 0.003 & 8.771 \\
\hline
\end{tabular}

Abbreviation: SD, standard deviation.

\section{Determination of the number of latent classes (Phase 2)}

The first step in determining the best-fitting model was to compare model fits based on log likelihood-based estimates (the BIC, CAIC, and other likelihood ratio values) and logical interpretabilities. Tables 2 and 3 show the selected model parameters for the three-class model and the competing models for the female and male samples. The three-class model had the lowest BIC and CAIC. However, the low AIC difference value shown in Table 3 indicates that the three- and fourclass models were similar in terms of approximating abilities. Although the three- and four-class models both seemed to fit the data, we selected the model with fewer classes for reasons of effectiveness. Thus, we extracted three-class models for both the female and male samples for comparisons.

\section{Latent class characteristics}

For the three-class LCA models, Figure 1 shows the distinguishable patterns of internet and smartphone addiction between the male and female samples in terms of conditional solution probabilities. A solution probability

Table 2 Indicators of fit for models (log likelihood based) in male sample

\begin{tabular}{llll}
\hline Class & BIC & AIC & CAIC \\
\hline I & 2970.5638 & 2954.6549 & 2975.5638 \\
2 & $2925.665 I$ & 2893.8473 & 2935.665 I \\
$\mathbf{3}$ & $\mathbf{2 9 1 6 . 3 6 3}$ & $\mathbf{2 8 6 8 . 6 3 6 2}$ & $\mathbf{2 9 3 1 . 3 6 3}$ \\
4 & 2932.5235 & $\mathbf{2 8 6 8 . 8 8 7 8}$ & 2952.5235 \\
5 & $295 I .557 \mathrm{I}$ & 2872.0125 & $2976.557 \mathrm{I}$ \\
6 & $2968.283 \mathrm{I}$ & 2872.8296 & $2998.283 \mathrm{I}$ \\
\hline
\end{tabular}

Note: Boldface indicates values of selected model.

Abbreviations: AIC, Akaike information criterion; BIC, Bayesian information criterion; CAIC, consistent Akaike information criterion. 
Table 3 Indicators of fit for models (log likelihood based) in female sample

\begin{tabular}{llll}
\hline Class & BIC & AIC & CAIC \\
\hline 1 & 4569.1972 & 4551.2051 & 4574.1972 \\
2 & 4492.1404 & 4456.1562 & 4502.1404 \\
3 & 4486.3599 & 4432.3836 & 4501.3599 \\
4 & 4493.1058 & 4421.1374 & 4513.1058 \\
5 & 4495.0191 & 4405.0586 & 4520.0191 \\
6 & 4511.9313 & 4403.9786 & 4541.9313 \\
\hline
\end{tabular}

Notes: Boldface indicates values of selected model.

Abbreviations: AIC, Akaike information criterion; BIC, Bayesian information criterion; CAIC, consistent Akaike information criterion.

close to 1 indicates a high likelihood of scoring high on the respective scale.

In the male group, latent class 1 ( $\mathrm{LC} 1 ; 24 \%$ of the entire male sample, $n=47$, low internet addiction, low smartphone addiction) exhibited low risks of internet and smartphone addiction, as demonstrated by the low probabilities ( 0.08 and 0.07 , respectively). Thus, this class was the group with the lowest addiction-related risks.

Latent class 2 (LC2; 50\% of the entire male sample, $\mathrm{n}=95$, moderate internet addiction, moderate smartphone addiction) contained individuals who seemed to take advantage of both the internet and smartphone in many ways in their everyday lives. However, their patterns of internet and smartphone use exhibited mild-to-moderate levels of addiction risk (the internet addiction risk of this class was slightly higher than that of the female LC1, and the smartphone addiction risk of this class was roughly half that of the female LC1). The probabilities of internet and smartphone addiction for this class were 0.25 and 0.22 , respectively.

Latent class 3 (LC3; 26\% of the entire male sample, $\mathrm{n}=36$, high internet addiction, high smartphone addiction) represented the subgroup of male students with the highest risk level for internet addiction (including the female classes). The likelihood rates of internet and smartphone addiction were 0.48 and 0.38 , respectively. Therefore, this subgroup represented the class with the greatest potential for addiction in the male sample.

In contrast, the members of female LC1 $(27.9 \%$ of the entire female sample, $n=83$, low internet addiction/low smartphone addiction) were the least likely to be addicted to the internet (0.07) or smartphone (0.22) among the entire sample. Based on this pattern, this class represented the female group with minimal risks of addiction to the internet and smartphone.

LC2 $(54.8 \%$ of the entire female sample, $n=154$, low internet addiction/high smartphone addiction) was a subgroup of female students who exhibited a low likelihood (0.18) of internet addiction and a relatively high likelihood
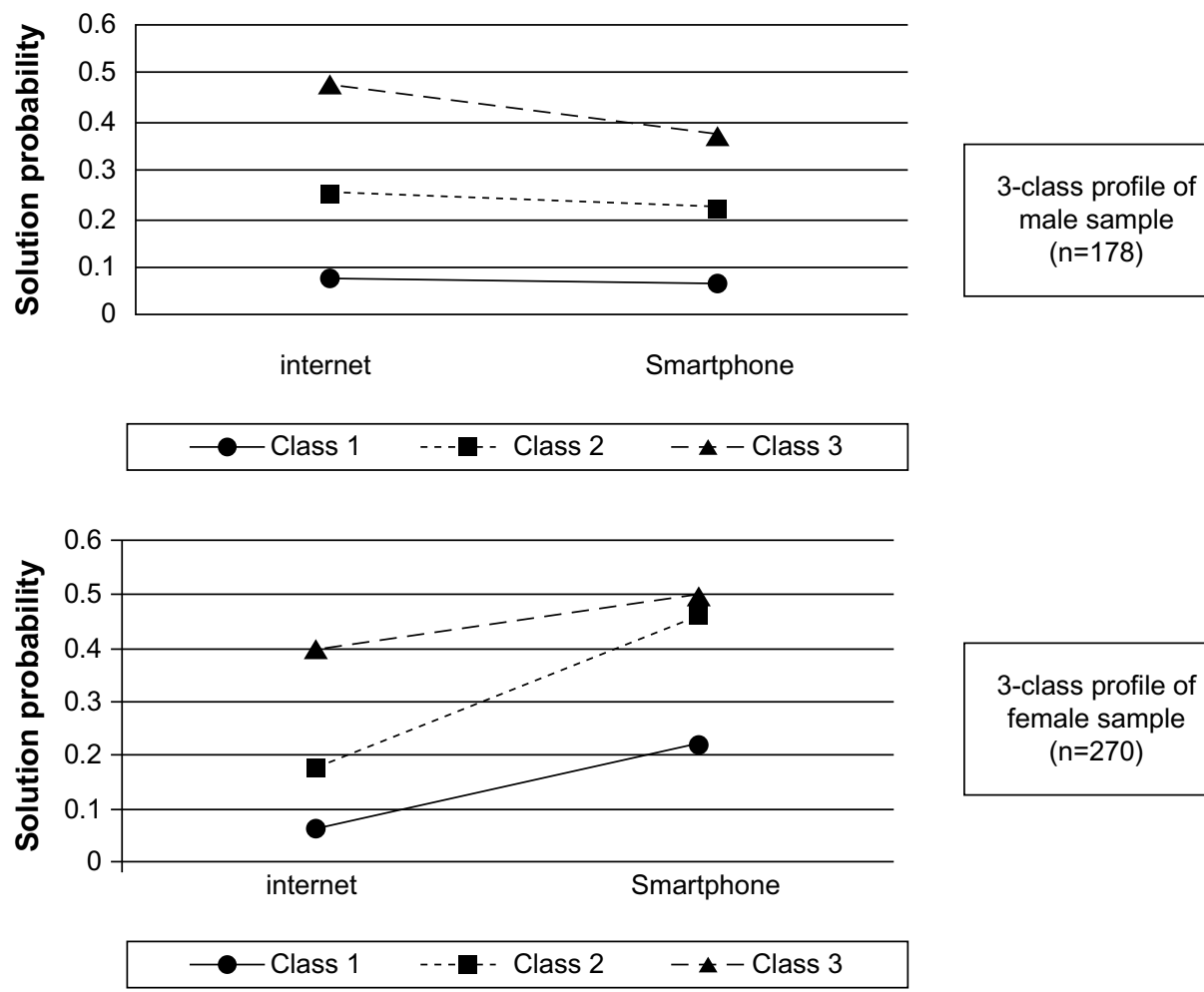

Figure I Latent class model in male and female samples. 
(0.46) of smartphone addiction. Although all classes exhibited a tendency to have a higher probability of smartphone addiction than internet addiction, this tendency was radically increased in class 2 (ie, smartphone addiction was more than twice as prevalent as internet addiction). In summary, this class appeared to represent a unique subgroup of females with a high risk of smartphone addiction and a low risk of internet addiction.

LC3 (17.3\% of the entire female sample, $n=33$, high internet addiction/high smartphone addiction) members tended to seriously indulge in both internet and smartphone use. Hence, the probabilities of internet $(0.40)$ and smartphone addiction (0.50) in this class were greater than those in the other classes. Furthermore, the probability of smartphone addiction in this class was the greatest of all classes (including those of the male sample). This class represented a typical group of people with low behavioral control.

\section{Cross-class comparisons (Phase 3)} Smartphone addiction

As mentioned earlier, the females exhibited a higher average level of smartphone addiction than did the males (male, $\mathrm{M}=59.68, \mathrm{SD}=21.08$; female, $\mathrm{M}=74.67, \mathrm{SD}=25.50$ ) (Table 1). To examine differences in characteristics across classes, ANOVAs were conducted on the total scores of the SAS and its six sub-factors; the results are illustrated in Table 4. Significant overall differences in the SAS total scores and the scores on the six sub-factors were confirmed across classes in both sexes. These findings indicate that the classes within each sex exhibited distinct patterns of smartphone addiction levels and that the classes were correctly clustered according to the specific features of smartphone addiction.

In post hoc analyses, LC1 scored significantly lower than any other subgroup within the female group on total smartphone addiction and smartphone-related problems across the six dimensions (all $P<0.001$ ). Members of LC3 exhibited the most seriously problematic smartphone use; however, LC3 and LC2 were not significantly different in smartphone addiction levels. Therefore, in contrast to LC1, LC2 and LC3 exhibited similar levels of smartphone addiction (LC2> LC1).

In contrast, in the male sample, three discrete classes were identified from post hoc analyses. LC1 exhibited the lowest level of smartphone-related problems and the lowest total SAS scores (all $P<0.001$ ). Additionally, LC2 exhibited SAS scores that were significantly higher than those of LC1 and significantly lower than those of LC3 (all $P<0.01$ ). Thus, the smartphone problem severity levels were as follows: LC3 had the most serious problems, LC2 exhibited a medium level of problems, and LC1 exhibited the lowest level of problems (ie, $\mathrm{LC} 3>\mathrm{LC} 2>\mathrm{LC} 1$ ).

\section{Internet addiction}

In contrast to the smartphone addiction pattern, the average internet addiction test score of the male participants was significantly higher than that of the females (male, $\mathrm{M}=35.65, \mathrm{SD}=11.72$; female, $\mathrm{M}=32.91, \mathrm{SD}=10.58$ ) (Table 1).

An overall $F$-test revealed that internet addiction levels were significantly different across the three latent classes of both the female and male groups (all $P<0.001$ ) (Table 4). Additionally, Bonferroni multiple comparison tests indicated that the female LC3 exhibited the greatest level of internet addiction within the sample. LC2 followed LC3, and LC1 exhibited the lowest level of internet addiction (ie, LC3 $>$ LC2 $>$ LC1). A similar pattern of internet addiction severity was observed in the male sample; LC3 exhibited the greatest addiction severity, followed by LC2, and LC1 exhibited the lowest level of addiction severity (ie, LC3 $>$ LC2 $>$ LC1). With the exception that the grand mean trends of the sexes were different, the general pattern of internet addiction was similar to that of smartphone addiction.

\section{Depression}

ANOVA and post hoc analyses were performed on the total BDI-I scores. A difference was found between the sexes: the female sample was significantly more depressed than the male sample $(F=11.127, P=0.001)$ (Table 1). Moreover, as observed in Table 4, all participants reported that they had been slightly depressed during the last week. All male classes reported mild levels of depression, and the females reported more moderate levels of depression, especially the LC3 group ( $\mathrm{M}=23.5, \mathrm{SD}=15.3)$. However, significant differences between the latent classes were not found (all $P>0.1$ ) (Table 4). The severities of internet and smartphone addiction were not factors that had significant influence on differentiating levels of depressive feelings.

\section{Anxiety}

Overall $F$-test and post hoc analyses revealed that both sexes showed significant differences across latent classes (all $P<0.001$ ). These findings illustrate that each class had a firmly independent anxiety level relationship (Table 1). 


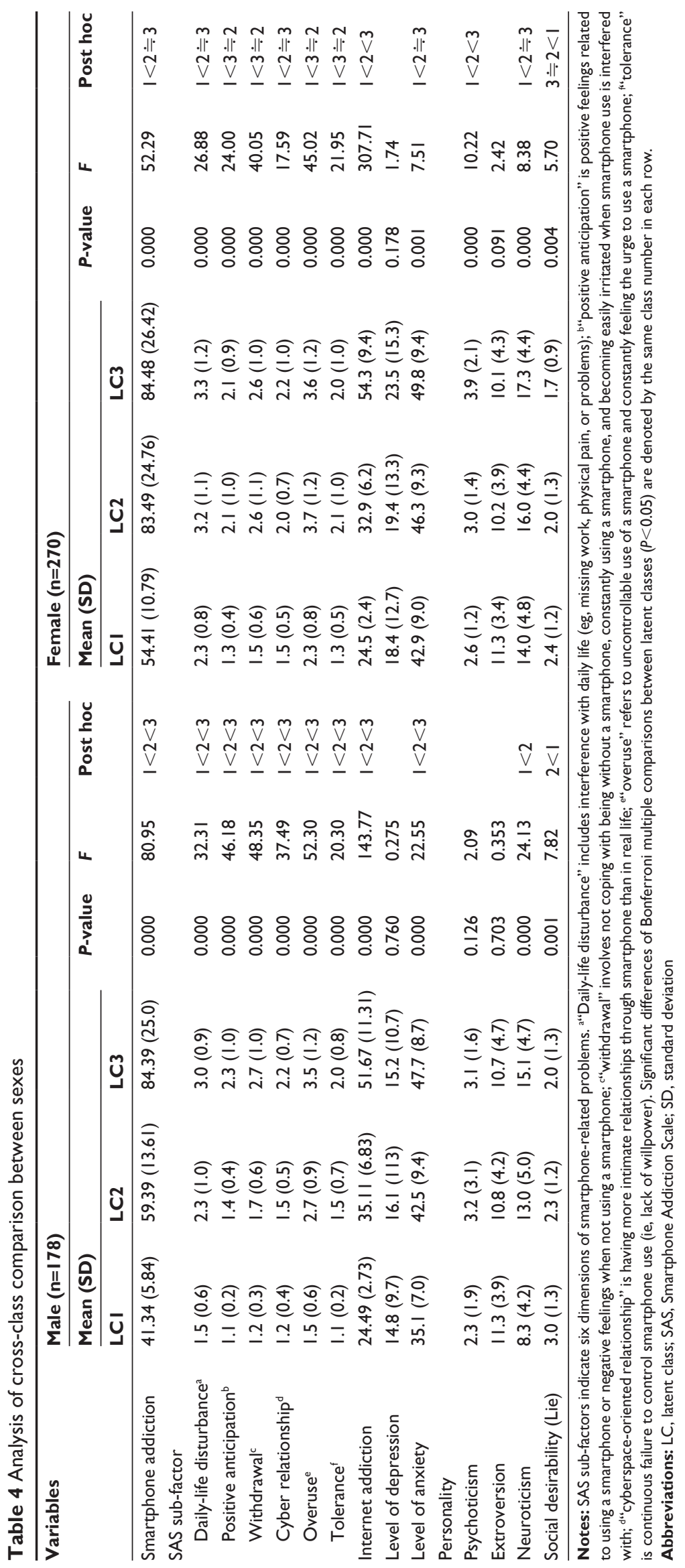


Although the total mean STAI-T score was meaningfully higher in the female group ( $\mathrm{M}=45.7, \mathrm{SD}=9.4)$ than in the male group $(\mathrm{M}=41.6, \mathrm{SD}=9.7)(F=19.78, P<0.001)$, the trends of the two groups were similar; ie, more severe internet and smartphone problems were accompanied by higher levels of anxiety (all $P<0.01 ; \mathrm{LC} 3>\mathrm{LC} 2>\mathrm{LC} 1$ ). A similar pattern was confirmed in the female group. Therefore, LC1 exhibited the lowest anxiety levels (all $P<0.01)$, and the anxiety levels of LC2 were greater than those of LC1 $(P<0.01)$ and lower than those of LC3 $(P<0.05)(\mathrm{LC} 3>\mathrm{LC} 2>\mathrm{LC} 1)$. No group's anxiety level exceeded the normal range (Table 4 ).

\section{Personality}

Significant differences between the sexes were found in the personality factors of the EPQ. Females $(\mathrm{M}=15.53$, $\mathrm{SD}=4.64)$ were more neurotic than males $(\mathrm{M}=12.19$, $\mathrm{SD}=5.33)(F=49.53, P<0.001)$, and males wanted to display socially desirable aspects of themselves to a greater degree than did females (male, $\mathrm{M}=2.44, \mathrm{SD}=1.31$; female, $\mathrm{M}=2.08$, $\mathrm{SD}=1.24)(F=8.77, P<0.01)($ Table 1$)$.

Moreover, a comparison of the latent classes revealed some differences. Specifically, the female group exhibited significant differences on the psychoticism $(F=10.22, P<0.001)$, neuroticism ( $F=8.38, P<0.001)$, and social desirability (Lie) scales $(F=5.698, P<0.01)$, and the difference in the extroversion scale was marginal $(F=2.42, P=0.091)$. The male groups exhibited differences in the neuroticism $(F=24.13, P<0.001)$ and social desirability scales $(F=7.82, P=0.001)$.

Post hoc analyses indicated that the females in LC3 exhibited psychoticism and neuroticism scores that were greater than those of LC1 (all $P<0.001$ ). Conversely, on the Lie scale, which indicates social desirability, LC1 was more socially desirable than were any of the other classes (all $P<0.05$ ). Regarding the male group, LC3 scored higher in neuroticism than LC2 or LC1 $(P<0.05)$, and LC1 was the least neurotic $(P<0.001)$. In contrast, the social desirability pattern of the males was similar to that of the females $(P<0.01)$ (Table 4).

\section{Discussion}

The concept of "internet addiction" or "smartphone addiction" could be unfamiliar to some researchers. In South-East Asian countries, however, the adverse impact of internet or smartphone addiction has been taken seriously and has led to a series of studies and social work by the government and health care givers to curb and alleviate the problem. A recent study by the Korean Ministry of Gender Equality and Family in 2013 reported that of the 1.63 million Korean adolescents, $17.9 \%$ comprised those with smartphone addiction. ${ }^{43}$ Moreover, over $24 \%$ of children diagnosed with internet addiction are hospitalized. ${ }^{44} \mathrm{~A}$ very similar trend is found in Japan. A study by the Japanese Ministry of Education has led to the recognition of the necessity for a government-managed system. ${ }^{45}$ Likewise, some specialized treatment centers and care-giving programs have been established in Europe (the outpatient clinic for behavior addictions in Mainz, Germany, and the Capio Nightingale Hospital in London, UK) and the USA (the inpatient centers RESTART internet addiction recovery program in Seattle, and digital detoxification and recovery center in Pennsylvania, USA) ${ }^{46}$ It implies that internet and smartphone addiction presents a significant global challenge.

The present study examined the relationship between internet and smartphone addiction with LCA, by subgrouping users based on their levels of usage and the severities of addiction-related problems. It has been noted that most researchers in this field tend to rely on correlation studies when reporting internet use and other psychological factors; however, the corresponding effect sizes are considerably small. ${ }^{47,48}$ Hence, it was necessary to treat measurements in a manner that allowed the more complex relationship between internet and smartphone addictions to be captured. Additionally, because concepts of these behavioral addictions were not clearly defined, the adoption of a latent profile model was necessary to comprehensively observe the relationship.

Moreover, to examine differences between the sexes in various personality traits, we separated the sample by sex prior to LCA. As expected, the initial analysis revealed that females were more vulnerable to smartphone addiction than internet addiction and that males exhibited the opposite pattern. Although some controversy remains, recent studies of smartphone addiction and low self-controllability ${ }^{49}$ and problematic mobile phone use ${ }^{50,51}$ have produced outcomes that are convergent with this study. However, conflicting results regarding differences between the sexes in internet use have also been reported. ${ }^{52-54}$ According to previous studies, male-female differences in internet addiction are due to differences in usage patterns, motivations, or purposes. For example, social use is significantly more important for females than it is for males, and leisure or interest-oriented use is more salient for males than it is for females. ${ }^{47,54-56}$ Although the literature has not reached a clear agreement, the findings of this study suggest that sex may influence examinations of the relationship between internet and smartphone addictions. 
In summary, based on examination of multiple models, we concluded that the three-class model was the most effective and informative in terms of elucidating the unique characteristics of each sex group. The pattern of addiction severity and related problems for the latent classes of both sexes was characterized by increasing severity from $\mathrm{LC} 1$ to $\mathrm{LC} 3$. This result is very comparable to a project study performed by the Korean National Information Society Agency in 2011. The study found that both adult and adolescent smartphone users could be divided into three different groups based on addiction proneness levels. Among adolescents, 2.2\% identified as belonging to the high-risk group, and $9.3 \%$ were in the low-medium-risk group. In adults, $1 \%$ of the users were in the high-risk group, and $6.7 \%$ were in the low-medium risk group..$^{57}$

Furthermore, multiple cross-comparison results revealed a trend that was common to both sexes: anxiety levels and neurotic personality traits increased with addiction severity levels. However, the scores on the Lie dimension of the $\mathrm{EPQ}$, which is an indication of social desirability level, were inversely related to the severity levels of the latent classes. For the females only, more severely addicted people exhibited more psychotic personality traits in the EPQ.

The present findings on personality are highly consistent with previous studies. A study on internet addiction among Chinese adolescents reported that the internet-addicted group scored higher in the neuroticism and psychoticism dimensions and lower in the Lie dimension than the control group. ${ }^{58}$ Similarly, internet addiction has been found to strongly positively correlate with neuroticism and negatively correlate with social desirability (Lie). ${ }^{59}$ Additionally, a study demonstrated that typical internet addicts exhibit anxiousness and problems with social contact. ${ }^{60}$

These findings are corroborated by the results of our study. It is well known that the neuroticism dimension encompasses moodiness and vulnerability to emotional stimuli, ${ }^{6}$ and these traits are similar to those of anxiety. Therefore, the observed positive relationships of neuroticism and anxiety with addiction severity are relevant. Furthermore, psychoticism is strongly associated with aggressiveness, socially unacceptable behavior, ${ }^{62-64}$ sensation-seeking, ${ }^{65}$ and low impulse control. ${ }^{66}$ As mentioned previously, the core features of behavioral addiction include the following: 1) continued engagement in a behavior despite adverse consequences; 2) diminished control over participation in the behavior; 3) compulsive participation; and 4) craving or appetitive urges that immediately precede engagement in the behavior. ${ }^{67,68}$ Therefore, the pattern of psychoticism observed in the female participants can be interpreted with the sensation-seeking behavior and impaired abilities to control smartphone usage. Eysenck and Eysenck ${ }^{37}$ reported that people who score high on the Lie scale tend to score low on psychoticism and extraversion. A negative relationship between the Lie dimension and sensation-seeking has also been reported ${ }^{65}$ Furthermore, Montag et al ${ }^{59}$ found a significant negative correlation between internet addiction and the Lie dimension.

Similarly to a previous study, ${ }^{69}$ we observed a significant correlation between internet and smartphone use in both sexes (male, $r=0.36, P<0.001$; female, $r=0.206, P=0.001$ ); the implications of the abovementioned studies can be employed to interpret this study. Because $\mathrm{Cao}$ and $\mathrm{Su}^{58}$ interpreted the Lie dimension as being beneficial for behavioral development, the Lie personality category can be identified as a category of social desirability or social conformity. Hence, it can be assumed that the LC1 participants of both sexes had the greatest desires to be socially desirable and exhibited the least unstable and impulsive traits. Consequently, we suggest that, for the people in $\mathrm{LC} 1$, the beneficial influence of the social desirability trait might have suppressed the other problematic traits related to internet and smartphone addiction. Because internet and smartphone problems were inversely related to social desirability traits, this supposition may be relevant for explaining the differences among classes.

Several limitations of this study should be considered. First, the participants were all college students who did not exhibit significant functional impairments. Hence, generalizing the results to a clinical setting could be difficult. However, because internet and smartphone addiction are a recently reported phenomenon and most users are young, this study reflects reality rather well. Additionally, given the paucity of valid research into smartphone-related problems, this study will provide information that will aid clinicians' understandings of the characteristics of smartphone users and related problems. Comparisons of the results from clinical populations with those of the present study are also recommended.

Second, it should be admitted that reported studies on internet or smartphone addiction are partially regionally limited, mainly in Asian countries. Accordingly, perceived importance of the issue has been overlooked in North American and European societies. However, as mentioned above ${ }^{46}$ recently growing concerns from some European countries and the US disprove the argument of a "culturally limited phenomenon" of internet and smartphone addiction. This would reflect increasing need for specialized help on the problem. 
Third, because the present study only measured severity and the problems caused by internet and smartphone addiction, no additional information was provided to support the findings. Some studies have identified personality and internet usage motives, ${ }^{70}$ the influence of internet usage purpose on internet addiction, ${ }^{59}$ and the effect of stress on smartphone addiction $^{49}$ to provide more valid explanations. Therefore, we suggest that further studies investigating and comparing latent classes should include information related to the number of hours of use, motives for use, and types of use (applications, games, or websites) to enhance clinical validity.

Lastly, the use of supporting neurocognitive tests or neurobiological markers would increase the validity of the results. Nonetheless, all of the measures that we employed are widely used and are considered effective and appropriate for determining the relevant psychological traits of individuals. Therefore, we suggest the use of neurological or biological evidence to enrich the results of future studies.

Overall, this study considered novel and noteworthy phenomena: internet and smartphone addictions. Little research has cast light on these issues, despite the increasing negative influence of these addictions on our lives. Therefore, the present study, which sought to explore the relationship between internet and smartphone addiction and related psychosocial problems, would be worthy of notice. We identified three latent classes based on addiction severity and confirmed the distinctive traits of these classes. The present results are expected to contribute to expanding the behavioral addiction field and to facilitate further research into its clinical implications.

\section{Acknowledgments}

Funding for this study was provided by a grant from the Korea Health Technology R\&D Project, Ministry of Health and Welfare, Republic of Korea (A120157). The funders had no role in the study design, collection, analysis or interpretation of data, writing of the manuscript, and the decision to submit the paper for publication. We thank the study participants who were willing to participate and complete the long questionnaire. We also thank Ji-Young Hwang for data collection and data analysis assistance.

\section{Author contributions}

All the authors contributed to the design of the study. All authors contributed to development of the manuscript, revised it critically, and gave their approval of this version to be published.

\section{Disclosure}

The authors report no conflicts of interest in this work.

\section{References}

1. Young KS. Internet addiction: the emergence of a new clinical disorder. Cyberpsychol Behav. 1998;1:13.

2. Beard KW, Wolf EM. Modification in the proposed diagnostic criteria for internet addiction. Cyberpsychol Behav. 2001;4:377-383.

3. Griffiths M. Internet addiction. Psychologist. 1999;12(5):245-250.

4. Ko CH, Yen JY, Chen CC, et al. Tridimensional personality of adolescents with internet addiction and substance use experience. Can J Psychiatry. 2006;51:887-894.

5. Internet World Statistics. 2013. Available from: http://www. internetworldstats.com/stats.htm. Accessed March 28, 2014.

6. De Leo JA, Wulfert E. Problematic internet use and other risky behaviors in college students: an application of problem-behavior theory. Psychol Addict Behav. 2013;27:133-141.

7. Kuss DJ, Griffiths MD. Internet gaming addiction: a systematic review of empirical research. Int J Ment Helath Addict. 2012;10: 278-296.

8. Batthyány D, Müller KW, Benker F, Wölfling K. [Computer game playing: clinical characteristics of dependence and abuse among adolescents]. Wien Klin Wochenschr. 2009;121:502-509. German.

9. King DL, Delfabbro P. Understanding and assisting excessive players of video games: a community psychology perspective. Aust Community Psychol. 2009;21:62-74.

10. Liu M, Peng W. Cognitive and psychological predictors of the negative outcomes associated with playing MMOGs (massively multiplayer online games). Comput Human Behav. 2009;25:1306-1311.

11. Peng W, Liu M. Online gaming dependency: a preliminary study in China. Cyberpsychol Behav Soc Netw. 2010;13:329-333.

12. Peters CS, Malesky LA. Problematic usage among highly-engaged players of massively multiplayer online role playing games. Cyberpsychol Behav. 2008;11:480-483.

13. Rehbein F, Kleimann M, Mössle T. Prevalence and risk factors of video game dependency in adolescence: results of a German nationwide survey. Cyberpsychol Behav Soc Netw. 2010;13:269-277.

14. Yee N. The psychology of MMORPGs: emotional investment, motivations, relationship formation, and problematic usage. In: Schroeder R, Axelsson A, editors. Avatars at Work and Play: Collaboration and Interaction In Shared Virtual Environments. London, UK: Springer-Verlag; 2006.

15. Yee N. The demographics, motivations and derived experiences of users of massively-multiuser online graphical environments. Teleoperators and Virtual Environments. 2006;15:309-329.

16. Dworak M, Schierl T, Bruns T, Struder HK. Impact of singular excessive computer game and television exposure on sleep patterns and memory performance of school-aged children. Pediatrics. 2007;120:978-985.

17. Chan PA, Rabinowitz T. A cross-sectional analysis of video games and attention deficit hyperactivity disorder symptoms in adolescents. Ann Gen Psychiatry. 2006;5:16-26.

18. Chiu SI, Lee JZ, Huang DH. Video game addiction in children and teenagers in Taiwan. Cyberpsychol Behav. 2004;7:571-581.

19. Hussain Z, Griffiths MD. Excessive use of massively-multi-player online role-playing games: a pilot study. Int $J$ Ment Health Addict. 2009;7:563-571.

20. Hussain Z, Griffiths MD. The attitudes, feelings, and experiences of online gamers: a qualitative analysis. Cyberpsychol Behav. 2009;12: 747-753.

21. Lemmens JS, Valkenburg PM, Peter J. Psychosocial causes and consequences of pathological gaming. Comput Human Behav. 2011;27: 144-152.

22. Kuss DJ, Griffiths MD. Internet and gaming addiction: a systematic literature review of neuroimaging studies. Brain Sci. 2012;2:347-374.

23. Griffiths MD. Internet addiction: internet fuels other addictions. Student Br Med J. 1999;7:428-429. 
24. Griffiths MD. Internet addiction - time to be taken seriously? Addict Res Theory. 2000;8(5):413-418.

25. American Psychiatric Association. Diagnostic and Statistical Manual of Mental Disorders (DSM-5). Arlington, VA: American Psychiatric Association; 2013.

26. Sim MS, Kim EM. The Smart Phone Use Survey 2011. Seoul: Korea Communications Commission Press; 2011:21-23.

27. Kuss DJ, Griffiths MD. Online social networking and addiction a review of the psychological literature. Int J Environ Res Public Health. 2011;8(9):3528-3552.

28. Kwon M, Lee JY, Won WY et al. Development and validation of a smartphone addiction scale (SAS). PLoS One. 2013;8(2):e56936.

29. Griffiths MD. Internet addiction. Psychologist. 1999;12(5):245-250.

30. Griffiths MD. A "components" model of addiction within a biopsychosocial framework. J Subst Use. 2005;10:191-197.

31. Yen CF, Tang TC, Yen JY, et al. Symptoms of problematic cellular phone use, functional impairment and its association with depression among adolescents in Southern Taiwan. J Adolesc. 2009;32(4):863-873.

32. Beck AT, Ward CH, Mendelson M, Mock J, Erbaugh J. An inventory for measuring depression. Arch Gen Psychiatry. 1961;4:53-63.

33. Rhee MK, Lee YH, Park SH, et al. A standardization study of Beck Depression Inventory I - Korean version (K-BDI): reliability and factor analysis. Korean J Psychopathol. 1995;4(1):77-95.

34. Spielberger CD. Manual for the State-Trait Anxiety Inventory (STA). Palo Alto, CA; Consulting Psychologists Press; 1983.

35. Sesti AM. State Trait Anxiety Inventory (STAI) in medication clinical trials. Quality of Life Newsletter. 2000;15-16.

36. Lim YJ, Lee SY, Kim JH. Distinct and overlapping features of anxiety sensitivity and trait anxiety: the relationship to negative affect, positive affect, and physiological hyperarousal. J Korean Clinic Psychol. 2005;24:439-449.

37. Eysenck HJ, Eysenck SBG. EdITS Manual. Eysenck Personality Questionnaire (Junior and Adult). San Diego: Educational and Industrial Testing Service; 1975.

38. Eysenck SBG, Lee HS. Cross-cultural study on the characteristics of personality dimensions: Korean and English. Korean $J$ Psychol. 1985;5(1):51-66.

39. Vermunt JK, Magidson J. Latent Gold 4.0 User's Guide. Bermont, MA: Statistical Innovations Inc.; 2005.

40. Magidson J, Vermunt JK. Latent class models. In: Kaplan D, editor. Handbook of Quantitative Methodology for the Social Sciences. Newbury Park, CA: Sage Publications; 2004:345-368. Available from: http://dx.doi.org/10.4135/9781412986311.n10.

41. Muthen BO. Latent variable mixture modeling. In: Marcoulides GA, Schumacker RE, editors. New Developments and Techniques in Structural Equation Modeling. Hillsdale NJ: Lawrence Erlbaum; 2001:1-33.

42. Nylund K, Bellmore A, Nishina A, Graham S. Subtypes, severity, and structural stability of peer victimization: what does latent class analysis say? Child Dev. 2007;78:1706-1722.

43. Kim AY. [ 240 thousand adolescents are in danger of smartphone addiction]. Naeil Shinmun. July 03, 2013. Korean. Available from: http:/ news.naver.com $/ \mathrm{main} / \mathrm{read}$. nhn? mode $=$ LSD\&mid $=$ sec\&sid $1=102 \&$ oid $=086 \&$ aid $=0002161531$. Accessed February 7, 2014 .

44. Ahn DH. Korean policy on treatment and rehabilitation for adolescents' internet addiction. In: National Youth Commission, editor. 2007 International Symposium on the Counseling and Treatment of Youth Internet Addiction. Seoul, Korea: National Youth Commission; 2007:49.

45. Majumdar A. Japan plans 'fasting camps' for Web-addicted children. Tech 2. 2013. Available from: http://tech2.in.com/news/general/japanplans-fasting-camps-for-webaddicted-children/912284. Accessed February 7, 2014.

46. Kuss DJ. Internet gaming addiction: current perspectives. Psychol Res Behav Manag. 2013;6:125-137.
47. Chen SK. Internet use and psychological well-being among college students: a latent profile approach. Comput Human Behav. 2012;28: 2219-2226.

48. Huang C. Internet use and psychological well-being: a meta-analysis. Cyberpsychol Behav Soc Netw. 2010;13:241-249.

49. Kim NS, Lee KE. Effects of self-control and life stress on smart phone addiction of university students. J Korea Soc Health Inform Stat. 2012;37(2):72-83.

50. Takao M, Takahashi S, Kitamura M. Addictive personality and problematic mobile phone use. Cyberpsychol Behav. 2009;12(5): 501-507.

51. Bianchi A, Phillips JG. Psychological predictor of problem mobile phone use. Cyberpsychol Behav. 2005;8(1):39-51.

52. Bimber B. Measuring the gender gap on the internet. Soc Sci $Q$. 2000;81(3):868-876.

53. Joiner R, Garvin J, Brosnan M, et al. Gender, internet identification, and internet anxiety: correlates of internet use. Cyberpsychol Behav. 2005;9(4):410-414.

54. Joiner R, Garvin J, Brosnan M, et al. Gender, internet experience, internet identification, and internet anxiety: a ten-year followup Cyberpsychol Behav. 2012;15(7):370-372.

55. Kang S. Disembodiment in online social interaction: impact of online chat on social support and psychosocial well-being. Cyberpsychol Behav. 2007;10:475-477.

56. Amichai-Hamburger Y, Ben-Artzi E. Loneliness and internet use. Comput Human Behav. 2003;19:71-80.

57. Shin KW, Kim DI, Jung YJ. Development of Korean Smart Phone Addiction Proneness Scale for Youth and Adults. Seoul: Korean National Information Society Agency Press; 2011:42-53.

58. Cao F, Su L. Internet addiction among Chinese adolescents: prevalence and psychological features. Child Care Health Dev. 2007;33: $275-281$.

59. Montag C, Jurkiewicz M, Reuter M. Low self-directedness is a better predictor for problematic internet use than high neuroticism. Comput Human Behav. 2010;26:1531-1535.

60. van Rooij AJ, Schoenmakers TM, van de Eijnden RJ, van de Mheen D. Compulsive internet use: the role of online gaming and other internet applications. J Adolesc Health. 2010;47:51-57.

61. Eysenck HJ, Eysenck SBG. Manual for the Eysenck Personality Inventory. San Diego: Educational and Industrial Testing Service; 1968.

62. Eysenck HJ, Eysenck SBG. Psychoticism as a Dimension of Personality. London: Hodder and Stoughton; 1976.

63. Eysenck HJ. Personality and factor analysis: a reply to Guilford. Psychol Bull. 1977;84:405-411.

64. Rushiton JP, Chrisjhon RD. Extraversion, neuroticism, psychoticism and self-reported delinquency: evidence from eight separate samples. Pers Individ Dif. 1980;2:11-20.

65. Eysenck S, Zuckerman M. The relationship between sensation-seeking and Eysenck's dimensions of personality. Br J Psychol. 1978;69: 483-487.

66. Eysenck HJ, Eysenck MW. Personality and Individual Differences: A Natural Science Approach. New York: Plenum Press; 1985.

67. Shaffer HJ. Strange bedfellows: a critical view of pathological gambling and addiction. Addiction. 1999;94:1445-1448.

68. Potenza MN. Should addictive disorders include non-substance-related conditions? Addiction. 2006;101:142-151.

69. Ha JH, Chin BS, Park DH, Ryu SH, Yu JH. Characteristic of excessive cellular phone use in Korea adolescents. Cyberpsychol Behav. 2008;11: 783-784.

70. Amiel T, Sargent SL. Individual differences in internet usage motives. Comput Human Behav. 2004;20:711-726. 


\section{Publish your work in this journal}

Neuropsychiatric Disease and Treatment is an international, peerreviewed journal of clinical therapeutics and pharmacology focusing on concise rapid reporting of clinical or pre-clinical studies on a range of neuropsychiatric and neurological disorders. This journal is indexed on PubMed Central, the 'PsycINFO' database and CAS.

The manuscript management system is completely online and includes a very quick and fair peer-review system, which is all easy to use. Visit http://www.dovepress.com/testimonials.php to read real quotes from published authors.

\footnotetext{
Submit your manuscript here: http://www.dovepress.com/neuropsychiatric-disease-and-treatment-journal
} 